\title{
USO DE FOTOGRAFIAS COMO RECURSO DIDÁTICO PEDAGÓGICO PARA DEFICIENTES INTELECTUAIS
}

\author{
Janaina Alves de Góis Santos \\ Marcia Regina Royer
}

\section{Resumo}

Os Deficientes Intelectuais (DI) apresentam alteração no desenvolvimento cognitivo, comportamento adaptativo e socioafetivo. A presente pesquisa objetiva abordar o uso de fotografias como estratégia pedagógica que desperta o interesse, favorece a memorização e facilita a compreensão de Ciências para DI. Este estudo de cunho qualitativo analisa imagens fotográficas registradas por alunos da Educação de Jovens e Adultos, de uma escola especializada na modalidade Educação Especial. Avaliou-se como a fotografia pode ser utilizada em sala de aula e quais aspectos cognitivos e socioculturais podem ser observados. Os resultados demonstraram a imagem fotográfica como uma opção viável que pode ser utilizada em diferentes disciplinas e que estimula a interação, a criatividade, autonomia e participação. Constatou-se que o aluno enquanto fotógrafo observa aspectos esquecidos ou não vistos, quando leitor demonstra sensações e visão ampliada da realidade e, por fim, como sujeito histórico vincula sua bagagem cultural, identidade e valores aos novos conhecimentos adquiridos.

Palavras-chave: deficientes intelectuais; ensino; fotografia.

\section{USE OF PHO'TOGRAPHS AS A PEDAGOGICAL EDUCATIONAL RESOURCE FOR INTELLECTUAL DISABILITIES}

\section{Abstract}

The Intellectual Disabled (ID) present alterations in cognitive development, adaptive and socio-affective behavior. The present research aims to approach the use of photographs as a pedagogical strategy that arouses interest, favors memorization and facilitates the understanding of Sciences for ID. This qualitative study analyzes photographic images recorded by students of Youth and Adult Education, from a school specialized in the Special Education modality. It was evaluated how photography can be used in the classroom and which cognitive and socio-cultural aspects can be observed. The results demonstrated the photographic image as a viable option that can be used in different disciplines and that stimulates interaction, creativity, autonomy and participation. It was found that the student as a photographer observes forgotten or unseen aspects, when the reader demonstrates sensations and an enlarged view of reality and, finally, as a historical subject he links his cultural background, identity and values to the new knowledge acquired.

Keywords: intellectual disability; teaching; photography.

\section{USO DE FOTOGRAFÍAS COMO RECURSO DIDÁCTICO PARA PERSONAS CON DISCAPACIDAD INTELECTUAL}

Resumen

Los Discapacidad Intelectual (DI) presentan alteraciones en el desarrollo cognitivo, comportamiento adaptativo y socio-afectivo. La presente investigación tiene como objetivo abordar el uso de la fotografía como uma estrategia pedagógica que despierta el interés, favorece la memorización y facilita la comprensión de las Ciencias para el DI. Este estudio cualitativo analiza imágenes fotográficas registradas por estudiantes de Educación de Jóvenes y Adultos, de una escuela especializada en la modalidad de Educación Especial. Se evaluó cómo se puede utilizar la fotografía en el aula y qué aspectos cognitivos y socioculturales se pueden observar. Los resultados demostraron la imagen fotográfica como una opción viable que se puede utilizar 
en diferentes disciplinas y que estimula la interacción, la creatividad, la autonomía y la participación. Se constató que el alumno como fotógrafo observa aspectos olvidados o invisibles, cuando el lector demuestra sensaciones y una visión ampliada de la realidad y, finalmente, como sujeto histórico vincula su bagaje cultural, identidad y valores a los nuevos conocimientos adquiridos.

Palabras clave: discapacidad intelectual; enseñando; fotografía.

\section{INTRODUÇÃO}

A educação como processo complexo e constante exige modificações e adequações para atender as demandas sociais. A escola, espaço privilegiado e legitimado para educação formal deve ofertar uma educação de boa qualidade fundamentada em princípios solidários, inclusivos e democráticos, para então, contribuir para a formação de cidadãos criativos, autônomos e reflexivos.

A Resolução (BRASIL, 2017) que homologou a Base Nacional Comum Curricular (BNCC) estabeleceu aprendizagens necessárias no processo formativo dos estudantes para a Educação Básica. Nessa proposta, dispõe-se que são necessárias as relações do conhecimento com a vida do aluno e o exercício da cidadania.

Frente a isso, faz-se necessário práticas pedagógicas que valorizem o desenvolvimento das capacidades, habilidades e potencialidades, que estimulem a criatividade, favoreça a compreensão da realidade e faça conexões com o cotidiano do indivíduo.

Pensando nestes aspectos, a contextualização dos conteúdos curriculares, a seleção de estratégias didáticas diversificadas, dinâmicas e interativas e a aplicação de procedimentos que favoreça o engajamento dos estudantes, obrigatoriamente, deve constituir o processo educativo. No entanto, quando se refere a Educação Especial e, consequentemente, os estudantes com deficiência intelectual que é o foco desta pesquisa, a mediação e interação didática com instrumento de ensino planejado, pode ser, fator determinante para o desenvolvimento de aspectos cognitivos, sociais e culturais.

Diante das transformações ocorridas na sociedade moderna, no âmbito da informação e do conhecimento, como novas formas culturais, inovações científicas e tecnológicas. Mediante a um contexto sociocultural cada vez mais conectado, o uso das tecnologias tornou-se indispensável na educação escolar.

Neste sentido, "a fotografia tornou-se um dos principais meios de acesso à experiência" (SONTAG, 1986, p. 20), pois possibilita o uso de recursos digitais de baixo custo, através da câmera do celular, instrumento comum a grande parte dos estudantes.

A fotografia é uma linguagem não-verbal amplamente utilizada na comunicação visual, cultural, econômica, jornalística e social (FERNANDES, 2005). A imagem fotográfica, tornou-se mecanismo tecnológico que faz parte do cotidiano dos indivíduos, seja nas redes sociais representando momentos vivenciados, na publicidade comercial através da internet ou como instrumento metodológico no registro de pesquisas, por exemplo, o compartilhamento de imagens, que por sua vez, ocorre de forma rápida e instantânea. No contexto escolar, livros didáticos são cada vez mais ilustrados utilizando os recursos visuais como fotografias, ilustrações e infográficos para explorar aspectos cognitivos, sociais, culturais, políticos entre outros, nos estudantes (FERNANDES, 2005).

Este estudo, justifica-se pelo número reduzido de publicações científicas que apresentem possibilidades de recursos didáticos para estudantes com Deficiência Intelectual (DI) que favoreça a valorização da identidade, especificidades e potencialidades. Ainda, a utilização da tecnologia através da câmera do celular, objeto comum entre grande parte dos estudantes. E por fim, no que se refere ao uso da fotografia, pesquisas indicam (KRAVOS, 2017; KARWATZKI, 2017) como via didática no ensino e na inclusão social de deficientes intelectuais, sendo uma área que pode ser explorada no âmbito acadêmico. 
Diante desta premissa, pretende-se, neste estudo, abordar o uso de fotografias como uma estratégia pedagógica didática que estimula a participação, desperta o interesse, favorece a memorização e facilita a compreensão de Ciências para estudantes com Deficiência Intelectual.

\section{REFERENCIAL TEÓRICO}

\section{Deficiência Intelectual e suas possibilidades}

Todos os seres vivos são geneticamente diferentes e as características individuais inerentes os constitui em um ser único. Nas premissas de Bueno e Oliveira (2019), o estudante com DI deve ser compreendido como sujeito histórico-social, passível de modificações e transformações, a partir do estímulo, interação e mediação, que ocorre através de práticas sociais e culturais com o meio e com outros sujeitos.

Neste sentido, adotando os pressupostos de Vigotski (1998), de que o comportamento cognitivo e o funcionamento intelectual são influenciados por fatores biológicos e sociais. E, no estudo de Shimazaki et al. (2018) que sublinha, também dentro da perspectiva de Vigotski, que os conhecimentos mediados no âmbito educacional e a experiência do estudante promovem o desenvolvimento de conceitos científicos e cotidianos em um processo interdependente e integrado. Ressalta-se, que o estudante aprende com atividades interativas e vinculadas a sua vida social. Desse modo, o estudante com DI tem barreiras orgânicas, mas a qualidade das interações culturais no caminho escolar é uma estratégia para a criança obter aquisições cognitivas através de relações práticas e verbais.

Nesta mesma concepção, Leonel e Leonardo (2014) discutem que o trabalho pedagógico, quando atrelado aos conhecimentos científicos, mediações do professor e às relações pode promover maior desenvolvimento cognitivo nos indivíduos.

Mediante aos aspectos mencionados, é notório compreender a complexidade que envolve o processo educativo de um estudante com DI, suas particularidades e necessidades para então, oportunizar situações de aprendizagem que favoreça seu desenvolvimento cognitivo, social e emocional.

Portanto, a seguir apresentamos a definição adotada pela Associação Americana de Psiquiatria (2014, p. 78) para DI que envolve

[...] déficits em capacidades mentais genéricas, como raciocínio, solução de problemas, planejamento, pensamento abstrato, juízo, aprendizagem acadêmica e aprendizagem pela experiência. Os déficits resultam em prejuízos no funcionamento adaptativo, de modo que o indivíduo não consegue atingir padrões de independência pessoal e responsabilidade social em um ou mais aspectos da vida diária, incluindo comunicação, participação social, funcionamento acadêmico ou profissional e independência pessoal em casa ou na comunidade.

Fundamentado nesta definição, frisamos que as alterações significativas no funcionamento intelectual e no comportamento adaptativo, quando exploradas com adaptações curriculares, procedimentos metodológicos diferenciados e interações sociais, promovem o desenvolvimento do sujeito. Para tanto, Santos (2012) indica a necessidade de encarar a deficiência como uma manifestação da diversidade humana.

Entre as dificuldades apresentadas por estes estudantes, estão as "dificuldades na linguagem expressiva e compreensiva, no aprendizado (recepção, memória e estímulos visuais) e na capacidade de articular pensamento e ação, na localização espaço - temporal" (BUENO; OLIVEIRA, 2019, p. 6). 
Portanto, ressaltamos que a prática pedagógica envolvendo alunos com DI tem seus desafios. No entanto, quando consideramos suas características e traçamos as ações pedagógicas adequadas ao estudante, é possível alcançarmos resultados positivos. Por exemplo, a participação, o envolvimento, a partilha de experiência e aproximação das atividades escolares ao cotidiano do estudante.

Nas premissas de Silva e Bueno (2019) e a Teoria Histórico Cultural defendida por Vygotsky, o estudante com DI aprende a partir das interações sociais, estímulo e mediação, isso porque o meio e as experiências têm influências determinante no indivíduo, e não somente o biológico.

Concordamos com as ideias de Leonel e Leonardo (2016), que versam sobre o desenvolvimento do homem vinculado as relações estabelecidas com as pessoas, o mundo e a natureza. Neste contexto, a escola, configura-se como espaço organizado culturalmente para a convivência social e mediações específicas, para produção de experiências que transformam o conhecimento em realidade, que favorece as modificações sociais e a configuração humana (WESTBROOK et al., 2010).

Como assevera Frizanco e Honora (2008), não existe um modelo pronto para o trabalho com DI. Contudo, compartilhar experiências, práticas educativas efetivas bem como, a postura adotada por educadores em sala de aula contribuirá para caminharmos no avanço do ensino da pessoa com ou sem deficiência.

Para isso, atividades que explorem a atenção, memória, raciocínio, percepção e visual, concentração e o pensamento abstrato são indispensáveis, bem como a manipulação de material concreto durante as situações de aprendizagem, buscando considerar o contexto real e natural dos estudantes.

A utilização de diferentes tipos de linguagens é recomendada para os estudantes com DI, mas também estão expressas como objetivos de aprendizagem para toda a Educação Básica como mostra a resolução que homologou a BNCC

4. Utilizar diferentes linguagens -verbal (oral ou visual-motora, como Libras, e escrita), corporal, visual, sonora e digital -, bem como conhecimentos das linguagens artística, matemática e científica para se expressar e partilhar informações, experiências, ideias e sentimentos, em diferentes contextos, e produzir sentidos que levem ao entendimento mútuo;

5. Compreender, utilizar e criar tecnologias digitais de informação e comunicação, de forma crítica, significativa, reflexiva e ética nas diversas práticas sociais (incluindo as escolares) para se comunicar, acessar e disseminar informações, produzir conhecimentos, resolver problemas e exercer protagonismo e autoria na vida pessoal e coletiva. (BRASIL, 2017).

É importante, salientar então, que ações educativas apresentadas neste texto direcionadas para estudantes com DI, estão de acordo, com as competências gerais esperadas para o ensino comum. Por isso, o uso da fotografia como recurso metodológico pode ser uma oportunidade de prática social que contextualiza o conteúdo e utiliza as tecnologias digitais.

Diante disso, a seguir apresentamos o uso da fotografia no processo educativo, e suas múltiplas possibilidades de utilização nas atividades escolares. 
Considerações acerca do uso da fotografia na prática escolar

Na história humana, a visão é um dos sentidos responsáveis pela percepção e comunicação com o mundo natural, junto da linguagem e da cultura, consolidadas desde os tempos remotos, em que o homem vivia em cavernas e fazia registros com utensílios rudimentares. Nesse sentido, Dondis (1997, p. 7) afirma que "a informação visual é o mais antigo registro da história humana. As pinturas das cavernas representam o relato mais antigo que se preservou sobre o mundo tal como ele podia ser visto há cerca de trinta mil anos".

O uso de imagens fotográficas como recurso pedagógico tem sido tema de estudos acadêmicos (SILVEIRA; ALVES, 2008; BARBOSA; PIRES, 2011; SANTANA, 2012; BODART, 2015; LIMA, 2015; SILVA, 2015), para intervenções em disciplinas como Arte, Geografia, História, Sociologia e também, Educação Infantil e Educação Ambiental. Por isso, através de uma análise reflexiva do uso da fotografia como recurso didático na prática educativa em diferentes áreas, este estudo sugere o uso do meio fotográfico como possibilidade metodológica para abordar os conteúdos de forma integrada e ensinar o estudante com DI a aplicar os conhecimentos em diferentes contextos.

Neste sentido, fazer uso da imagem fotográfica e da linguagem visual como uma alternativa didática para o ensino é aproveitar os recursos acessíveis e de custo reduzido, para as mudanças educacionais necessárias, oportunizando uma forma de ensinar e aprender que envolva o aprendiz no processo. Deste modo, possibilitará o que sugere Moran (2012, p. 21) "a educação tem de surpreender, cativar, conquistar os estudantes a todo momento".

Diante de tal desafio, discutiremos o meio fotográfico como instrumento para formação de estudantes críticos, reflexivos e observadores, através do olhar atento para as relações dialógicas entre o homem e o ambiente. É possível enxergar o potencial implícito na foto e fazer uso na prática docente para formar sujeitos solidários e conscientes, e concordamos com o apontamento de que

O meio fotográfico se transforma assim em um importante instrumento que permite a formação em conhecimentos transversais, relacionados à educação para a cidadania, à solidariedade e ao respeito a grupos culturalmente diferentes. (ALVARADO et al., 2010, p. 75).

Portanto, conforme sugere a referência o meio fotográfico pode ser utilizado em diferentes contextos educativos para o trabalho disciplinar e interdisciplinar dos conteúdos curriculares, estimulação de valores e atitudes contribuindo para formação do indivíduo. A partir de uma foto registrada pelo próprio aluno ou não, é possível despertar o interesse, a observação e a análise de aspectos discutidos, impulsionam o desenvolvimento do respeito mútuo, da valorização da diversidade, da formação de um pensamento sustentável, entre outros. Ainda, Alvarado et al. (2010) acrescenta que as capturas fotográficas permitem a transposição de conhecimentos relacionados com o letramento científico, a cidadania e os valores éticos, aspectos indispensáveis para uma educação de boa qualidade.

Estudos sugerem (BORGES; ARANHA; SABINO, 2010; BARBOSA; PIRES, 2011) explorar as capturas fotográficas como estratégia didática partindo da variável, de que o registro fotográfico pelas mãos dos estudantes permite apontar a percepção dos sujeitos ao meio em que estão inseridos, instigando a sensibilização e conscientização, bem como, a apropriação do tema abordado. Por isso, a partir de uma fotografia registrada pelo próprio aprendiz, é possível despertar o interesse, familiarizá-lo com os aspectos estudados, instigá-lo a observar o mundo natural e compreendê-lo a partir da linguagem visual. 
Desse modo, conforme sugere Barbosa e Pires (2011), a fotografia pode ser capaz, de forma lúdica e atrativa, de integrar o indivíduo ao meio ambiente, logo, uma possibilidade tecnológica atrativa para as aprendizagens essenciais que favorecem a formação do indivíduo.

A ilustração, o desenho e a fotografia são formas importantes de comunicação que relacionam o conhecimento de forma criativa e dinâmica, a partir da sua leitura visual o indivíduo expressa seu ponto de vista sobre o mundo e suas conexões com o que sabe e o que está aprendendo. Partindo dessa premissa, Silveira e Alves (2008) acrescentam que esse processo desvela a ligação do contexto sociocultural e o do funcionamento orgânico, no qual as imagens reais se conectam com as imagens mentais.

Corroborando com esta linha de pensamento, Lopes (2005, p. 09) apresenta:

A linguagem fotográfica é vista como uma prática, que pode ser estimulada na escola [...]. Colocando em foco as múltiplas formas de ver e ser visto, o ato fotográfico desponta como mais um caminho de problematização da vida, que nos permite, através da mediação técnica da câmera fotográfica, registrar, decifrar, ressignificar e recriar o mundo e a nós mesmos.

A fotografia torna-se um instrumento capaz de transmitir a percepção do fotógrafo e daquele que a visualiza a imagem e a descreve, sendo possível notar suas emoções, seus interesses, sentimentos e possivelmente, sua visão de mundo. Ainda, é capaz de forma lúdica e atrativa integrar o indivíduo ao meio ambiente (BARBOSA; PIRES, 2011).

Partindo da variável sugerida em pesquisas (BORGES et al., 2010; BARBOSA; SILVA, 2011) o registro de fotográfico pelas mãos dos estudantes permite apontar a percepção dos sujeitos ao meio em que estão inseridos, abrindo portas para sensibilização e conscientização, bem como, a apropriação do tema abordado. Por isso, este artigo permeia a visão de aluno-fotógrafo com DI.

Neste tocante, acreditamos no potencial deste recurso para o desenvolvimento de diferentes linguagens com estudantes DI estimulando aspectos cognitivos e sociais. Assim, ao fotografar expõe sua cultura e relação com o mundo.

Em concordância com Bodart (2015), a fotografia favorece a percepção daqueles que são convidados a descrever a cena capturada. No qual, o espectador é um protagonista ao contribuir com seus aspectos afetivos e cognitivos, no qual o leitor da fotografia ou imagem imprime sua percepção do mundo aliada à sua bagagem histórico-cultural. Para Sardelich (2006, p. 456):

A denotação refere-se ao significado entendido "objetivamente", o que "objetivamente" se vê na imagem, a descrição das situações, figuras, pessoas e ou ações em um espaço e tempo determinado. A conotação refere-se às apreciações do intérprete, aquilo que a imagem sugere e/ou faz pensar o leitor.

A fotografia, embora seja objetiva, permite análise subjetiva a partir das implicações do observador, além de múltiplos olhares quando contemplada em grupo. Deste modo, "a fotografia não captura o objeto, mas o olhar que apreende esse objeto e que não é individual, mas construído social e conjunturalmente" (CAVEDON, 2005, p. 16). Nesta proposta, a captura da imagem sensibiliza sujeitos, imprime suas identidades e valores na relação com o conhecimento e, então, contribui para a formação acadêmica e cultural.

Nesta perspectiva, o estudante se sente pertencente ao trabalho, compartilha suas origens e favorece a ampliação de sua consciência sobre a realidade. Ao compartilhar suas fotos promove uma ação cooperativa, a valorização das particularidades individuais e a diversidade do grupo.

Salientamos ainda, que o uso de fotografia facilita a problematização, questionamentos e que pode resultar em discussões positivas sobre a temática estudada. Por isso, o trabalho com este 
instrumento pode ser compreendido pelo estudante como uma forma de comunicação através de signos, a linguagem não verbal.

Uma fotografia traz muitas informações e, de acordo com Alves et al. (2008, p. 3)

[...] a imagem fotográfica é obra pensada e elaborada pelo fotógrafo ou artista, que a compõe a partir de suas referências pessoais, profissionais, sociais e culturais, em um processo muito mais amplo do que a mera operação técnica do aparelho e que será recebida pelo leitor fruidor, que também carrega sua própria bagagem cultural.

De acordo com o posicionamento de Alves (2008), a partir de uma imagem capturada, podemos obter aspectos identitários e culturais do fotógrafo e/ou do contexto e sujeitos em questão. Ademais, as experiências dos próprios estudantes, ao analisarem uma fotografia, podem se confrontar com as da imagem original, impulsionando sua imaginação, capacidade de argumentação e bagagem cultural.

Quando o aprendiz faz captura de imagens, por consequência, preparou sua visão, isso porque, o fotógrafo por algum motivo escolheu determinada cena, talvez inconscientemente, mas o fato é que poderia ter utilizado uma infinidade de possibilidades. E que mesmo sem o domínio dos conhecimentos técnicos, atentou-se para a iluminação e a distância adequada do objeto para obter o melhor ângulo.

O aluno contemporâneo está habituado a visualização de imagens em diferentes contextos e, por esse motivo, a utilização da fotografia estimula o desenvolvimento do indivíduo na prática escolar (FERNANDES, 2005), podendo resultar, ainda, em um ambiente estimulador e criativo para o desenvolvimento da criticidade, autonomia, motivação e participação, aspectos essenciais para a aprendizagem. Sendo assim, o uso das fotografias, com o apoio das tecnologias digitais, se constitui como um direito de aprendizagem que potencializa a cultura digital, permite a integração do conhecimento acadêmico, social e cultural.

\section{METODOLOGIA}

No presente trabalho, a fotografia foi utilizada como um recurso didático na aprendizagem de estudantes com Deficiência Intelectual, tendo em vista as aprendizagens essenciais das áreas do conhecimento: Ciências da Natureza (Ciências) e Linguagens (Língua Portuguesa e Arte), conforme preconiza a BNCC para o Ensino Fundamental dos anos iniciais $\left(1^{\circ}\right.$ a $5^{\circ}$ ano).

O público-alvo são constituídos por 10 estudantes com DI, da Educação de Jovens e Adultos (cinco do gênero feminino e cinco do gênero masculino), de uma escola especializada na modalidade da Educação Especial, em um município paranaense, na qual a Associação de Pais e Amigos dos Excepcionais (APAE) é mantenedora. Estes alunos estudam no período vespertino, com idade entre 16 e 45 anos, etapa única, que compreende as dimensões do Ensino Fundamental - Anos Iniciais (do $1^{\circ}$ ao $5^{\circ}$ ano). A identificação dos estudantes se dará por meio da letra E seguida pela sequência em numeração arábica (E1, E2, E3... E10).

Abordamos a imagem e a câmera fotográfica do celular como instrumentos tecnológicos em atividades escolares de estudantes com DI.

Utilizou-se a pesquisa descritiva de cunho qualitativo por meio de observação e de análise das imagens registradas pelos aprendizes, sua participação, envolvimento e a vinculação do conteúdo com a compreensão do seu cotidiano.

Destacamos que, primariamente, para coleta das fotografias apresentadas neste estudo, foram realizadas intervenções pedagógicas por meio de um trabalho interdisciplinar sobre a tema 'Plantas, e sua importância para os seres vivos', desenvolvido por três professoras da turma 
(Regente I e II, professora de Arte). As capturas fotográficas foram utilizadas como modo de envolver os estudantes, estimular a apropriação de linguagens, bem como, a comunicação e a interação.

As imagens analisadas fazem parte do material produzido por estudantes com DI durante o ano letivo de 2020. Neste período, houve a suspensão das aulas presenciais, substituídas por aulas mediadas de forma remota, conforme o Decreto n 4230/2020 (PARANÁ, 2020), que dispõe sobre as medidas para o enfrentamento do Coronavírus (COVID-19).

A proposta metodológica e atividades didáticas aplicadas na turma ocorreram de acordo a com a Proposta Pedagógica Curricular da Instituição que alinhou os conteúdos de Ciências a Base Nacional Curricular Comum (BNCC). E, conforme preconiza estes documentos norteadores devese abordar as diferentes explicações sobre o mundo, os fenômenos da natureza e as transformações produzidas pelo homem.

Seguimos os fundamentos teóricos do conteúdo curricular contextualizado, minimizando "as limitações de uma educação científica centrada na mera transmissão de conhecimentos" destacada por Cachapuz et al., (2011, p. 36). Ao adotarmos a interdisciplinaridade, apresentamos uma aprendizagem dinâmica, a oportunidade de superação da compartimentalização das disciplinas e o intercâmbio dos saberes ${ }^{1}$.

Para esta investigação, as atividades foram planejadas, desenvolvidas e executadas por três professoras. Sendo possível estabelecer as conexões com as disciplinas de Língua Portuguesa e Arte, através de um objeto de estudo da disciplina de Ciências.

Conforme disposto na tabela 1 , as duas professoras regentes da turma e a professora de Arte, elencaram os conteúdos, objetivos e procedimentos de ensino, em consonância com o que preconiza os documentos norteadores (BNCC e PPC) para cada disciplina, mas tendo em vista o estudo e a investigação das plantas como objeto de conhecimento e organismo vivo.

Tabela 1: Síntese da organização pedagógica das atividades sobre a temática 'as plantas e sua importância para os seres vivos' que resultou nas imagens fotográficas analisadas

\begin{tabular}{|c|c|}
\hline \multicolumn{2}{|c|}{$\begin{array}{l}\text { ÁREA DO CONHECIMENTO: CIÊNCIAS DA NATUREZA } \\
\text { Objeto de conhecimento: Plantas }\end{array}$} \\
\hline \multicolumn{2}{|c|}{$\begin{array}{l}\text { Base Nacional Curricular Comum: Vida e Evolução } \\
\text { Proposta Curricular na dimensão da escola especializada: Seres Vivos no Ambiente. }\end{array}$} \\
\hline $\begin{array}{l}\text { Objetivos: } \\
\text { Evidenciar a presença das partes das plantas na } \\
\text { casa dos estudantes; }\end{array}$ & $\begin{array}{c}\text { Procedimentos de Ensino: } \\
\text { Utilização da tecnologia do celular para o registro } \\
\text { das fotografias; }\end{array}$ \\
\hline $\begin{array}{l}\text { Aproximar o conteúdo da realidade dos alunos; } \\
\text { Incentivar o uso dos recursos visuais através da } \\
\text { câmera; }\end{array}$ & $\begin{array}{l}\text { Registro com imagens de plantas ou parte dela } \\
\text { presentes na sua alimentação. }\end{array}$ \\
\hline $\begin{array}{l}\text { Instigar a criatividade, autonomia, descoberta e o } \\
\text { espírito investigativo. }\end{array}$ & \\
\hline \multicolumn{2}{|c|}{$\begin{array}{c}\text { AREA DO CONHECIMENTO: LINGUAGENS } \\
\text { Disciplina: Língua Portuguesa }\end{array}$} \\
\hline Disciplina: I & gua Portuguesa \\
\hline
\end{tabular}

${ }^{1}$ Envolve o "saber" constituído de conhecimentos, habilidades, atitudes e valores e "saber fazer" dispõe sobre a mobilização do saber para resolver situações da vida cotidiana, exercício da cidadania e mundo do trabalho (BRASIL, 2017). 
DOI: $10.12957 /$ teias.\%Y.54913

Base Nacional Curricular Comum (BNCC)/Proposta Curricular na dimensão da escola especializada: Leitura, Oralidade e Escrita

\begin{tabular}{|c|c|}
\hline $\begin{array}{l}\text { Comunicar de maneira verbal e não verbal, } \\
\text { apoiada por gravuras, símbolos e outros. }\end{array}$ & $\begin{array}{c}\text { Procedimentos de Ensino: } \\
\text { Textos não verbais (com uso de fotos) como forma } \\
\text { de expressão e interação entre os códigos da } \\
\text { linguagem }\end{array}$ \\
\hline \multicolumn{2}{|c|}{$\begin{array}{c}\text { AREA DO CONHECIMENTO: LINGUAGENS } \\
\text { Disciplina: Arte }\end{array}$} \\
\hline \multicolumn{2}{|c|}{$\begin{array}{c}\text { Base Nacional Curricular Comum (BNCC): } \\
\text { - Música; } \\
\text { - Artes visuais } \\
\text { Proposta curricular na dimensão da escola especializada: } \\
\text { nentos da linguagem: altura; intensidade; timbre; melodia; ritmo; duração } \\
\text { - Materialidade/processos de criação } \\
\text { - Arte e tecnologia }\end{array}$} \\
\hline Objetivos: & Procedimentos de ensino: \\
\hline $\begin{array}{c}\text { Explorar os elementos da linguagem através da } \\
\text { música; }\end{array}$ & Uso do vídeo - com interpretação oral; \\
\hline $\begin{array}{c}\text { Estimular a expressão artística através do } \\
\text { desenho; }\end{array}$ & $\begin{array}{l}\text { Desenho ilustrativo relacionado com o tema da } \\
\text { música; }\end{array}$ \\
\hline $\begin{array}{l}\text { Expressar seus conhecimentos sobre o tema } \\
\text { abordar de forma oral e visual; }\end{array}$ & $\begin{array}{l}\text { As fotos para validação das atividades; } \\
\text { Uso do vídeo - com interpretação oral; }\end{array}$ \\
\hline $\begin{array}{l}\text { Estimular a expressão artística através do } \\
\text { desenho; }\end{array}$ & $\begin{array}{l}\text { Desenho ilustrativo relacionado com o tema da } \\
\text { música; }\end{array}$ \\
\hline $\begin{array}{l}\text { Expressar seus conhecimentos sobre o tema } \\
\text { abordar de forma oral e visual; }\end{array}$ & As fotos para validação das atividades; \\
\hline
\end{tabular}

Fonte: Elaborado pelas autoras, 2020.

Conforme disposto no quadro 1, o educador deve adequar as estratégias e intervenções pedagógicas que contemplem o conteúdo e favoreçam a vinculação com o contexto real, a fim de facilitar a apropriação do conhecimento. No que se refere aos procedimentos de ensino utilizados, conforme indicam Silva e Silva (2016), consideramos os recomendados para estudantes com DI, em que o professor considera as condições de aprendizagem e o nível de competência curricular do estudante. Desta forma, seguimos com a aplicação de atividades didáticas de orientação individual e coletiva, com vídeos de ensino, cruzadinha, pesquisa e investigação, caça palavras, análise de situações problema, discussões através de conversas virtuais, textos narrativos, informativos, desenhos esquemáticos, leitura de imagens e registros fotográficos.

Assim, debruçamo-nos, a seguir, nos resultados obtidos, a fim de contribuir com as nossas considerações acerca da fotografia como uma ferramenta didática, que pode enriquecer o ensino de Ciências de forma dinâmica e interativa. 


\section{RESULTADOS E DISCUSSÃO}

A educação científica e tecnológica favorece o desenvolvimento futuro. Não há como pensar na formação de cidadãos sem o saber científico. Assim, o letramento científico deve ultrapassar "a mera reprodução de conceitos científicos, destituídos de significados, de sentidos e de aplicabilidade" (ABREU, 2010, p. 18). Por isso, a educação em Ciências deve promover uma aprendizagem que favoreça a contextualização dos conteúdos, seleção e aplicação de diferentes estratégias didático-pedagógicos e procedimentos de ensino, a partir dos quais seja valorizada a diversidade presente no âmbito escolar. Ainda, tornar os conteúdos curriculares significativos considerando o contexto social e temporal constitui uma necessidade educacional para as diferentes modalidades de ensino.

O aluno com DI necessita de situações em que manipulem e explorem os objetos, neste caso, os alimentos ou plantas presentes no quintal de casa, como revela Miranda (2014).

Neste trabalho a fotografia foi utilizada com instrumento de captura do cotidiano envolvendo o tema estudado, como sugerido nos estudos de Bodart (2015). Assim, os estudantes ao fotografarem os vegetais e suas respectivas partes encontrados em casa como verifica-se na figura 1, registraram sua identidade e cultura, somado a interação com o uso da tecnologia.

Estes estudantes foram desafiados a observar seu contexto e as relações com a natureza a partir desta prática. Segundo Barbosa e Pires (2011) a fotografia permite registrar observações de situações ou cenários esquecidos ou não observados.

Nesta mesma linha, Bodart (2015, p. 97) revela que "os registros dos alunos serão fruto de suas percepções e escolhas, uma vez que ao registrar a cena cotidiana o aluno-fotógrafo realizou escolhas [...]", neste sentido, concordamos que os estudantes escolheram quais alimentos ou plantas iriam fotografar, como também, inseriram a sua realidade, quando afirmaram que o feijão era a única semente presente em casa.

É importante destacar alguns aspectos visíveis na figura 1 como, por exemplo, o enquadramento do objeto na câmera, efeito da luz ou da sombra, indicando a percepção visual aguçada dos estudantes. Sabemos que estes estudantes não possuem conhecimentos técnicos, no entanto, a captura da imagem, permitiu que todos observassem a cena registrada.

Figura 1: Fotografias registradas pelos estudantes E1 e E2, respectivamente
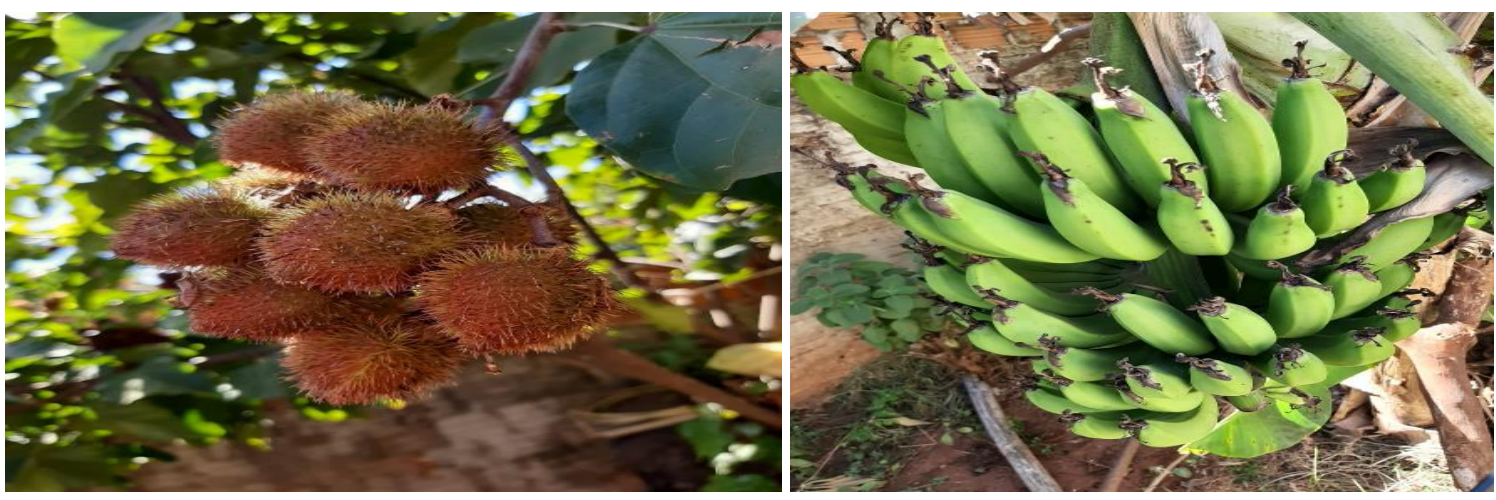

Fonte: Autoras, 2020.

Além disso, durante este período de aulas remotas, as fotografias instituíram-se como um instrumento de acompanhamento e mediação pedagógica na realização das atividades. Para isso, visualizávamos as fotos das atividades em tempo real e realizávamos as adequações e correções junto do aluno e responsável. 
$\mathrm{Na}$ continuidade da dinâmica, alguns estudantes tiveram a iniciativa de nomear as plantas ou partes dela na fotografia, para facilitar a visualização e percepção visual dos demais, utilizando aplicativos de layout (Figura 2). É preciso destacar, a demonstração de autonomia e o interesse pelas ferramentas tecnológicas no celular e aplicativo, quando consideramos que são estudantes com leitura e compreensão em processo de desenvolvimento.

Figura 2: Fotografias e Montagens realizadas pelos estudantes E3 e E10
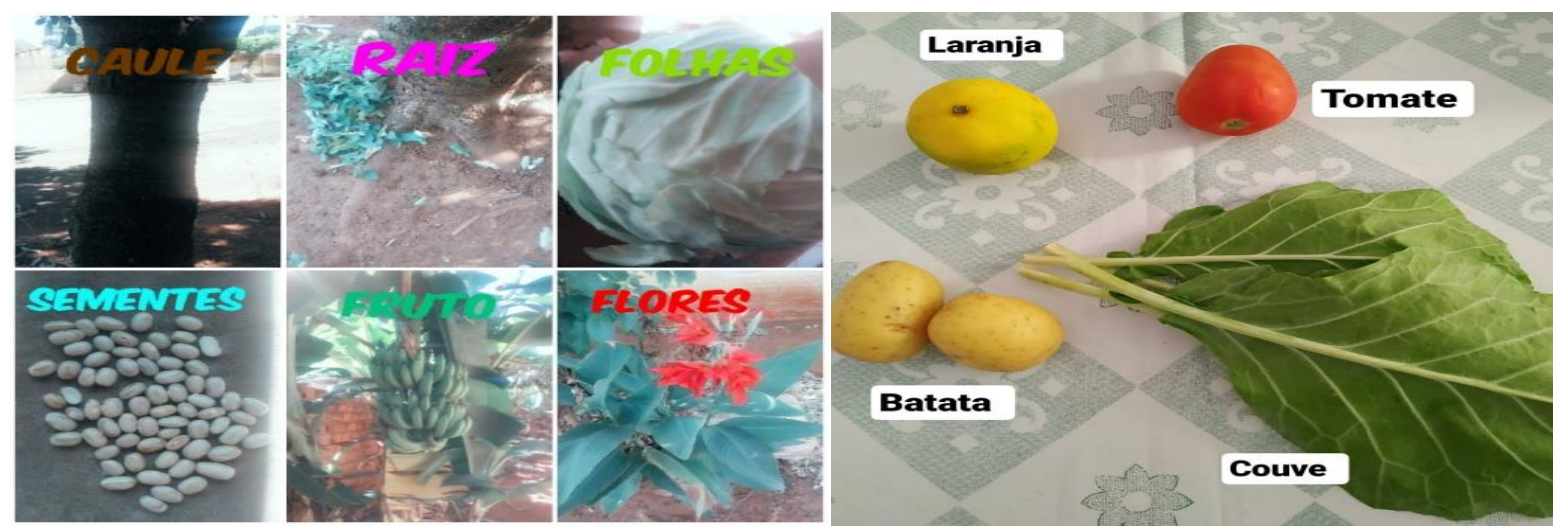

Fonte: Autoras, 2020.

Em concordância com Bender (2014), durante as aulas foi evidenciada a preferência dos sujeitos por tarefas em que poderiam demonstrar sua criatividade em relação àquelas que lhes exigiam apenas o desenvolvimento de exercícios ditos normativos. Nesse sentido, há indícios de que o uso de fotografias aprimora habilidades dos estudantes para a contemporaneidade.

Ainda, o trabalho colaborativo, o companheirismo e a motivação se fizeram presentes durante as atividades com os sujeitos. Tendo em vista que as fotografias necessitavam ser passíveis de visualização, por vezes, almejando ajudar os colegas que desconheciam o modo de usar o aplicativo para fotografia, estudantes se colocavam à disposição para auxiliar os demais. Isso sinaliza que ocorreu cooperação, parceria e trabalho em equipe.

Todavia, independente de qual seja a deficiência, o ambiente e as relações sociais são parte da construção do sujeito. Para isso, a alteração biológica, que neste caso é a Deficiência Intelectual, não seja uma fonte de limitações, então através do secundário (relações sociais entre os participantes e o objeto de estudo) será possível possibilitar ao estudante a organização intelectual que necessita para relacionar a teoria à prática (ANACHE; MARTINEZ, 2009).

Partindo deste aspecto, os estudantes realizaram uma prática de Ciências, que envolvia a germinação da semente de feijão, explorando aspectos estudados previamente sobre o desenvolvimento da planta. No entanto, deveriam registrar através de fotografias o crescimento do pé de feijão e compartilhar com os colegas. Para tanto, receberam todas as instruções necessárias para o plantio e cuidados necessários.

Os resultados obtidos sobre a prática sobredita encontra-se na figura 3. Ao analisar as fotografias, podemos observar plantas em diferentes estágios de desenvolvimento, o que indicou responsabilidade, comprometimento e rotina para estes aprendizes. Cabe enfatizar que os estudantes tinham como missão diária colocar água no copo, expor ao sol e assegurar os cuidados necessários para o crescimento da planta de feijão.

Silveira e Alves (2008) salientam que a fotografia assume três aspectos: o fotógrafo, o espectador (que olha) e a imagem (seja a cena, objeto ou indivíduo). Neste contexto, observamos 
a responsabilidade e o comprometimento em cada imagem, no qual estes sujeitos recorreram a imaginação e a criatividade para fotografarem os melhores ângulos.

Neste sentido, as imagens fotográficas proporcionam ao sujeito a linguagem visual, a observação e o registro de momentos que podem contribuir para formação do indivíduo, ao compartilhar suas impressões, transmitir seus sentimentos e a maneira de ver as coisas.

Figura 3: Imagens fotográficas da atividade prática sobre germinação de feijão dos estudantes E3, E1 e E10, respectivamente
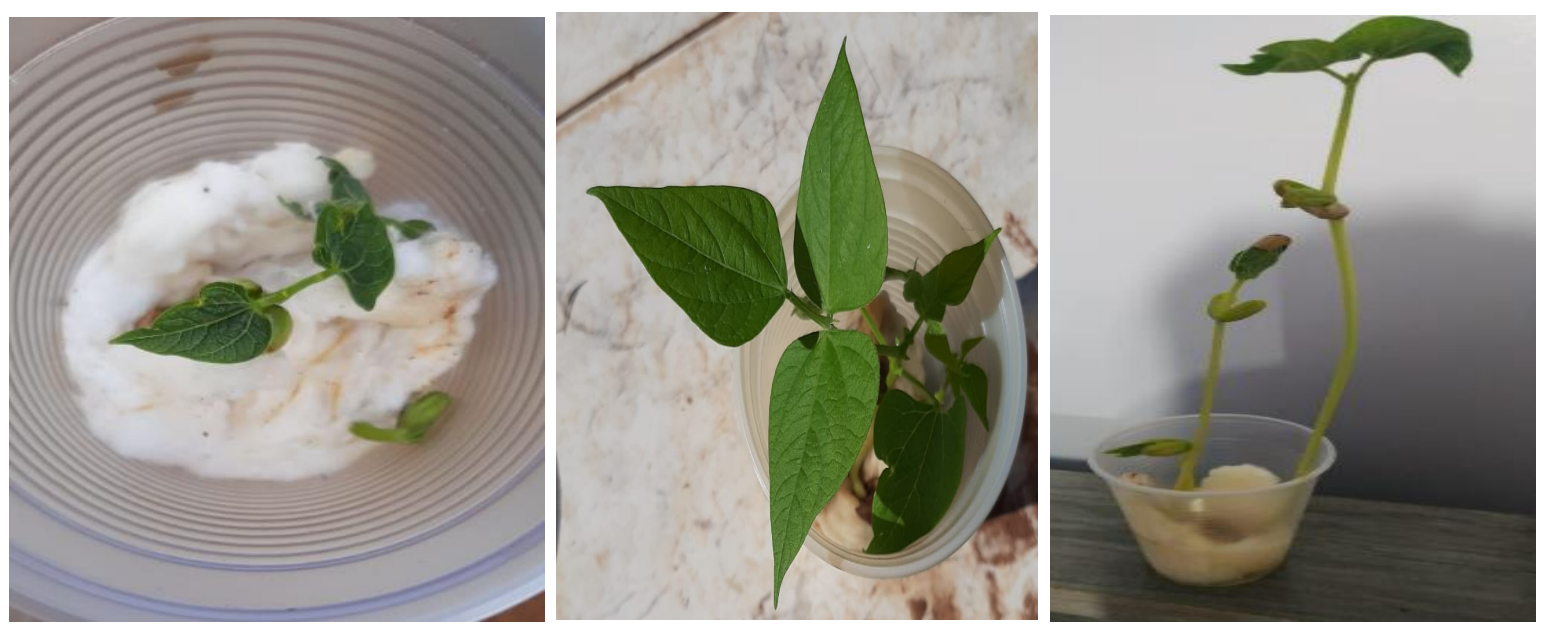

Fonte: Autoras, 2020.

Alguns estudantes não tiveram sucesso na germinação, entretanto tal fato suscitou em diferentes modos de engajamento na atividade, por meio da formulação de hipóteses para o não desenvolvimento da semente. Um dos estudantes, por exemplo, fez uso de argumentos que justificavam a chuva e o frio como possíveis causas da perda de seu experimento. Percebe-se que relacionou o fato ocorrido com fenômenos da natureza, vinculou o conhecimento com sua realidade e sua capacidade argumentativa para buscar soluções para o problema apresentado. Além disso, se evidencia a organização intelectual das informações e suas relações com o contexto. Neste momento, a prática permitiu a ressignificação da experiência.

Os resultados demonstram que ocorreu apropriação do conhecimento por parte dos estudantes, o que corroboram com Pozo (2002, p. 66), em que salienta que a aprendizagem envolve três sistemas que se interagem "os resultados de aprendizagem (o que se aprende), os processos de aprendizagem (como se aprende) e as condições práticas (em que se aprende)".

$\mathrm{Na}$ interação com os estudantes, foram apresentados desafios enfrentados pelo agricultor para cultivar culturas importantes para consumo humano, a exemplo do feijão. O professor atuou como facilitador, orientando grupos ou trabalhando com os alunos individualmente, utilizando todos os meios estimular o interesse, a investigação e recompensar os resultados obtidos com o avanço da pesquisa e do desenvolvimento de artefatos, conforme propõe Bender (2014).

Concordamos com o estudo de Santana e Sofiato (2019) que reafirmam a necessidade de intervenções pedagógicas, adaptações e atividades diferenciadas para atender as singularidades e potencialidades do estudante, por isso, indicamos procedimentos de ensino com ênfase no envolvimento dos estudantes, instrução cooperativa, tutoria de colegas e o ensino recíproco.

A interdisciplinaridade como relatam Azevedo e Andrade (2007) promove interação entre o sujeito, a sociedade e o conhecimento, tornando o ambiente escolar vivo e dinâmico. Permite criar elos de ligação entre professores e conteúdos disciplinares, permitindo uma reflexão mútua e 
uma análise sobre as potencialidades e desafio, garantido a identidade da disciplina sem perder o potencial de aprendizagem, mas tornando rico e integrado o processo educativo.

Neste sentido, destacamos que a disciplina de Arte fez parte do trabalho interdisciplinar e por meio da linguagem audiovisual, explorou o conteúdo estudado referente ao objeto de conhecimento das 'plantas' junto com elementos da disciplina como linguagem, expressões artísticas e visuais.

Isso porque, a professora trabalhou uma música intitulada 'Planta Bambolê' para explorar os elementos e a identidade da disciplina, contemplou oralidade, compreensão e vinculou com os aspectos abordados na disciplina de Ciências de forma integradora e dinâmica. Desta forma, interdisciplinaridade consolidou seu papel de estabelecer conexões entre as disciplinas para facilitar a compreensão e proporcionar ao estudante uma visão ampliada da realidade e dos conteúdos.

Explorando sua criatividade, coordenação motora, estimulando a imaginação. Segue alguns registros das fotografias das ilustrações realizadas pelos estudantes após a abordagem do tema com uso da música supracitada (Figura 4).

A ilustração foi realizada pelos estudantes em casa, e por isso, deviam registrar através de imagem fotográfica para compartilhamento com os colegas. Ressaltamos que foram inúmeras as tentativas realizadas por estes estudantes para enquadramento do desenho, o foco, a luz, mas o empenho e o envolvimento nas atividades os fizeram fotografar várias vezes e indicou para os professores a necessidade de mediações espaço-temporal.

No entanto, o aluno contemporâneo, seja ele com DI ou não, está habituado ao uso das tecnologias, aplicativos, visualização de imagens em diferentes contextos. Por isso, sua utilização na prática educacional estimula o engajamento e o desenvolvimento do indivíduo.

Figura 4: Ilustrações da música Planta Bambolê dos estudantes E10 e E9 respectivamente
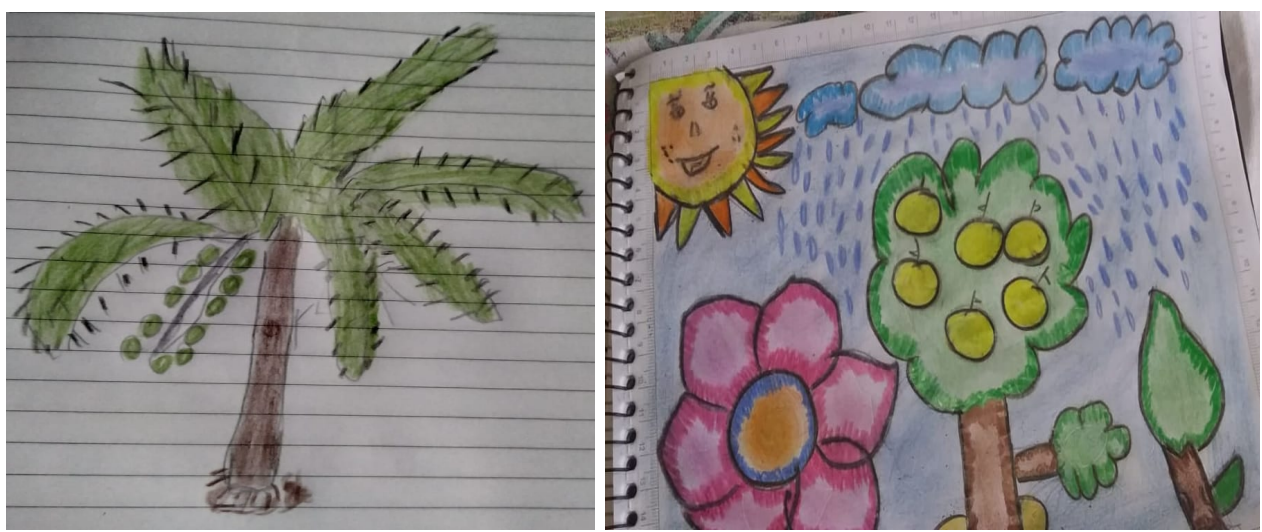

Fonte: Autoras, 2020.

Ainda, tais aspectos e mecanismos permitiram a partir do aparelho celular, criar um ambiente virtual, estimulador e produtivo para o desenvolvimento da criticidade, autonomia e a participação dos estudantes com DI. Reafirmando os argumentos de Silva e Oliveira (2010), que defendem os recursos midiáticos como instrumento pedagógico, crítico e criativo, o que contribui para a qualidade da educação e formação do cidadão. Dessa forma, as imagens fotográficas, além de potencializarem a cultura digital preconizada na BNCC (BRASIL, 2018), permitiram a integração do conhecimento acadêmico, social e cultural.

Os estudantes, a partir das fotografias, observaram aspectos do seu cotidiano, fizeram registros dos seus experimentos, demonstraram admiração e autonomia por sentirem-se ativos no processo. Assim, o uso de imagens fotográficas mostrou-se um instrumento pedagógico para 
aprendizagem dos estudantes com DI. Ademais, agregou informações relevantes para a prática docente, por exemplo, na percepção do estudante quanto ao mundo real e as conexões com a natureza e nos aspectos diagnósticos a serem trabalhados com os estudantes para que ensino e a mediação promova o estímulo da linguagem, do pensamento e a apropriação do conhecimento.

\section{CONSIDERAÇÕES FINAIS}

O estudante DI constitui-se sujeito histórico cultural com alterações cognitivas e adaptativas que podem ser trabalhadas a partir de mediações e interações significativas. Diante disso, a fotografia e o ato de fotografar podem ser uma via metodológica em potencial e as suas múltiplas utilizações em diferentes áreas de estudo, indicaram como uma possibilidade tecnológica atrativa para as aprendizagens essenciais que favorecem a formação cidadã.

Através da câmera do celular, uma tecnologia de custo reduzido e acessível a grande parte dos estudantes, tornou possível desenvolver atividades que estimulam a interatividade, motivação e valorização dos interesses. Ainda, foi capaz de partilhar a percepção do fotógrafo e promover uma linguagem descritiva, sendo possível observar indicativos de emoções, interesses, e, possivelmente, sua visão de mundo.

Poder-se-á dizer que, a fotografia pode ser utilizada como uma alternativa didáticapedagógica viável e efetiva para o ensino interdisciplinar, que permite um trabalho docente reflexivo e estabelece conexões entre os saberes científicos de Ciências. Considerando a temática estudada das 'plantas, e sua importância para os seres vivos', mas que pode ser aplicada em diferentes disciplinas.

Indicamos o uso da fotografia, como um recurso didático no ensino e aprendizagem para estudantes com DI, visto que ficou evidenciado que o registro fotográfico, permite que o estudante aprenda, ensina e extrai conhecimentos, reconstrói a realidade, estimula a comunicação, a participação e o engajamento dos estudantes. Ainda, é capaz de instigar percepções, sensibilizar o fotógrafo e o leitor das imagens, que demonstra a sua visão da realidade e o quanto sabem sobre o assunto. Portanto, ela transmite conhecimento sobre o sujeito fotógrafo, leitor da imagem e do espaço em que foi registrada.

Faz-se necessário adequações constantes para transpor os desafios do ensino e aprendizagem voltados para Educação Especial. Neste sentido, a experiência visual através do meio fotográfico posiciona-se como um recurso didático em potencial para o ensino de Ciências para estudantes com DI.

Por fim, a fotografia e as diferentes percepções que ela investiga a consolida como um recurso didático versátil, que pode ser amplamente utilizado no contexto escolar, inclusive por inseri-la como instrumento tecnológico no ensino de Ciências para estudantes com DI

\section{REFERÊNCIAS}

ABREU, Geusa Spitz Alcoforado de. Metodologia de projetos em ciências. Florianópolis: Publicações do Instituto Federal de Santa Catarina, 2010. 73 p.

ALVES, Jefferson Fernandes. et al. Fotografia e educação: alguns olhares do saber e do fazer. In: XXXI Congresso Brasileiro de Ciências da Comunicação. 2008, Natal-RN. Anais eletrônicos... Natal: 2008. Disponível em: http://www.intercom.org.br/papers/nacionais/2008/resumos/R3-0259-1.pdf Acesso em: 08 jul. 2020.

ALVARADO, María del Mar Ramírez. et al. Fotografia criativa para as crianças: a alfabetização audiovisual através da fotografia. Comunicação \& Educação. São Paulo, v. 15, n. 3, p. 67-80, 2010. 
ANACHE, Alexandra Ayach; MARTINEZ, Albertina Mitijáns. O sujeito com deficiência mental: processos de aprendizagem na perspectiva histórico-cultural. In: JESUS, Denise Meyrelles de et al. (orgs). Inclusão, práticas pedagógicas e trajetórias de pesquisa. Porto Alegre: Mediação, 2009. p. 43-57.

ASSOCIAÇÃO AMERICANA DE PSIQUIATRIA. DSM - 5. Manual Diagnóstico e Estatístico de Transtornos Mentais. Trad. Maria Inês Corrêa Nascimento, et al. Revisão técnica Aristides Volpato Cordioli, et al. Porto Alegre: Artmed, 2014.

AZEVEDO, Maria Antonia Ramos de; ANDRADE, Maria de Fátima Ramos de. O conhecimento em sala de aula: a organização do ensino numa perspectiva disciplinar. Educar em Revista. n. 30, p. 235-250, UFPR - Curitiba, 2007.

BARBOSA, Leila Cristina Aoyama; PIRES, Dario Xavier. O uso da fotografia como recurso didático para educação ambiental: Uma experiência da educação problematizada. Experiências em Ensino de Ciências. Cuiabá, v. 6, n. 1, p. 69-84, 2011.

BENDER, Willian N. Aprendizagem baseada em projetos: educação diferenciada para século XXI. Porto Alegre: Penso, 2014.

BODART, Cristiano das Neves. Fotografia como recurso didático no ensino de sociologia. Em Tese. Florianópolis, v. 12, n. 02, p. 81-102, 2015.

BORGES, Marilia Dammski; ARANHA, José Marcelo; SABINO, José. A fotografia de natureza como instrumento para educação ambiental. Ciência e Educação. Bauru, v. 16, n. 1, p. 149-161, 2010. BRASIL. Resolução CNE/CP 2/2017. Diário Oficial da União, Brasília-DF, 22 de dezembro de 2017, Seção 1 , p. 41-44. Disponível em: http://basenacionalcomum.mec.gov.br/images/historico/RESOLUCAOCNE CP222DEDEZ EMBRODE2017.pdf. Acesso em: 07 jul. 2020.

BRASIL. Base Nacional Comum Curricular: versão aprovada. Brasília: MEC, 2018. Disponível em: http://basenacionalcomum.mec.gov.br/images/BNCC_EI_EF_110518_versaofinal_site.pdf.

Acesso em: 17 jul. 2020.

BUENO, Olga Mara; OLIVEIRA, Rita de Cássia da Silva. O desenvolvimento adulto do sujeito deficiente intelectual e a relação com a Educação para Jovens e Adultos (EJA): uma análise, a partir da perspectiva docente. Revista Educação Especial. Santa Maria, v. 32, p. 1-15, 2019.

CACHAPUZ, António.; Gil-PEREZ, Daniel.; CARVALHO, Ana Maria Pessoa de; PRAIA, João; VILCHES, Amparo. A necessária renovação do ensino das ciências. 3. ed. São Paulo: Cortez, 2011.

CAVEDON, Neusa Rolita. Fotoetnografia: a união da fotografia com a etnografia no descortinamento dos não ditos organizacionais. O\&.S. Salvador, v. 12, n. 35, p.13-27 2005. Disponível em: http://www.scielo.br/pdf/osoc/v12n35/a01v12n35.pdf. Acesso em: 08 jul. 2020.

DONDIS, Donis A. Sintaxe. da linguagem visual. 2. ed. São Paulo: Martins Fontes, 1997.

FERNANDES, Hylio Laganá. A fotografia como mediadora subversiva na produção do conhecimento. $240 \mathrm{f}$. Tese (Doutorado em Educação). Universidade Estadual de Campinas, Campinas, 2005.

HONORA, Marcia; FRIZANCO, Mary Lopes Esteves. Esclarecendo as deficiências: Aspectos teóricos e práticos para contribuir com uma sociedade inclusiva. São Paulo: Ciranda Cultural, 2008.

KRAVOS, Ingrid Pelissari. A fotografia como objeto material na construção da historiografia da Apae de Getúlio Vargas pelos alunos deficientes. In: I Seminário Internacional de Cultura Material e Arqueologia, 2017, Passo Fundo - MG. Anais eletrônicos...Disponível em: https://www.upf.br/ uploads/Conteudo/ppgh/anais-seminario-internacional/2017/kravos.pdf -Acesso em: 02 mar.2021. 
KARWATZKI, Walter. Fotografia para inclusão de jovens com necessidades especiais de educação. Educação, Artes e Inclusão. Santa Maria, v. 13, n.1, p. 200-227, 2017.

LEONEL, Waléria Henrique dos Santos; LEONARDO, Nilza Santos Tessaro. Concepções de professores da educação especial (APAE s) sobre a aprendizagem e desenvolvimento do aluno com Deficiência Intelectual: um estudo a partir da teoria Vigotskiana. Revista Brasileira Educaşão Especial. Marília, v. 20, n. 4, p. 541-554, 2014.

LOPES, Ana Elisabete. Ato fotográfico e processos de inclusão: análise dos resultados de uma pesquisa-intervenção. In: $28^{a}$ Reunião Anual da ANPED, 2005, Caxambu-MG. Anais eletrônicos... Caxambu: 2005. Disponível em: http://28reuniao.anped.org.br/textos/gt15/gt151254int.pdf Acesso em: 09 jul. 2020.

LIMA, Diana Aparecida de. Num mundo de selfies: A fotografia como recurso pedagógico para Educação Infantil. 115 f. Dissertação (Mestrado em Educação). Universidade Federal do Paraná, Curitiba PR, 2015.

MIRANDA, Amanda Drzewinsk de. Contextualizando a matemática por meio de projetos de trabalho em uma perspectiva interdisciplinar: foco na deficiência intelectual. 162 f. Dissertação (Mestrado em Ensino de Ciências e Tecnologia). Universidade Tecnológica Federal do Paraná, Ponta Grossa - PR, 2014.

MORAN, José Manuel. A educação que desejamos: Novos desafios e como chegar lá. 5. ed. Campinas - SP: Papirus, 2012.

POZO, Juan Inácio. Aprendizes e mestres: a nova cultura da aprendizagem. Porto Alegre: Artes Médicas, 2002.

PARANÁ. Decreto no 4230/2020 aprovado em 16/03/2020. Dispõe sobre as medidas para enfrentamento da emergência de saúde pública de importância internacional decorrente do Coronavirus - COVID-19. Disponível em: http://www.aen.pr.gov.br/arquivos/Decreto 4230.pdf. Acesso em: 10 jul. 2020.

SANTANA, Ronaldo Santos; SOFIATO, Cássia Geciauskas. Ensino de Ciências para todos: uma experiência com deficiência intelectual. Educação. Santa Maria, v. 44, p. 1-27, 2019.

SANTOS, Daísy Cléia Oliveira dos; Potenciais dificuldades e facilidades na educação de alunos com deficiência intelectual. Educaşão e Pesquisa, São Paulo, v. 38, n. 04, p. 935-948, out./dez. 2012.

SARDELICH, Maria Emilia. Leitura de imagens, cultura visual e prática educativa. Cadernos de Pesquisa. São Paulo, v. 36, n. 128, p. 451-472, 2006.

SHIMAZAKI, Elza Midori; AUADA, Viviane Gislaine Caetano; MENECASSI, Renilson Jose; MORI, Nerli Nonato Ribeiro. O trabalho com o gênero textual história em quadrinhos com alunos que possuem deficiência intelectual. Revista Brasileira Educação Especial, Marília, v. 24, n. 1, p. 121142, jan./mar., 2018.

SILVA, Alessandra Cristina. A importância da fotografia como recurso pedagógico no ensino de artes visuais. 54 f. Monografia (Especialização em Ensino de Artes Visuais e Tecnologias Contemporâneas). Escolas de Belas Artes da Universidade Federal de Minas Gerais. Belo Horizonte - MG. 2015.

SILVA, Rosilma Ventura de.; OLIVEIRA, Elisangela Mercado de. As possibilidades do uso do vídeo como recurso de aprendizagem em salas de aula do $5^{\circ}$ ano. In: V EPE AL - Encontro de Pesquisa em Educação de Alagoas, Maceió, 2010. Anais eletrônicos [...] Disponível em: http://www.pucrs.br/ciencias/viali/tic literatura/artigos/videos/Pereira Oliveira.pdf Acesso em: 24 ago. 2020.

SILVA, Luiz Everson da; SILVA, Lenir Maristela. O ensino de Ciências na perspectiva da metodologia de aprendizagem por projetos em curso de Licenciatura. Revista Brasileira de Ensino de Ciências e Tecnologia, Ponta Grossa, v. 9, n. 2, p. 237-249, mai./ago. 2016. 
SILVEIRA, Larissa Souza; ALVES, Josineide Vieira. O uso da fotografia na Educação Ambiental: Tecendo Considerações. Pesquisa em Educação Ambiental. v. 3, n. 2, p. 125-146, 2008.

SONTAG, Susan. Ensaios fotográficos. Lisboa, Dom Quixote, 1986.

VYGOTSKY, Lev Semenovich. A formação social da mente: o desenvolvimento dos processos psíquicos superiores. 6 ed. São Paulo: Martins Fontes, 1998.

WESTBROOK, Robert B.; TEIXEIRA, Anísio; ROMÃO, José Eustáquio; RODRIGUES, Verone Lane. (orgs.). John Dewey. Recife: Fundação Joaquim Nabuco, Editora Massangana, Coleção Educadores, 2010. 136p.

Submetido em setembro de 2020 Aprovado em janeiro de 2021

\section{Informações das autoras}

Janaina Alves de Góis Santos

Secretaria do Estado do Paraná - SEED

E-mail:sjanaina@escola.pr.gov.br

ORCID: https://orcid.org/0000-0003-2088-7027

Link Lattes: http://lattes.cnpq.br/ 4816800409228774

Marcia Regina Royer

Universidade Estadual do Paraná - UNESPAR, Campus Paranavaí

E-mail:marciaroyer@yahoo.com.br

ORCID: https://orcid.org/0000-0002-6369-9440

Link Lattes: http://lattes.cnpq.br/70720996754014 